\title{
Depth Profile Of Titanium Alloy (Ti-6Al-4V) and Residual Stress Measured by Using X-Ray Diffraction after Metal Cutting Assisted by High-Pressured Jet Cooling Evaluation of Etching Methods: ION Beam (EDOS) and Electro- Chemical Etching
}

\author{
Manouchehr Vosough ${ }^{(1,2)}$, Ping Liu $^{3}$, and Inge Svenningsson ${ }^{(4,5)}$ \\ 1 Ph.D. Student, Luleå University of Technology, 2 lecturer, University of Gävle Sweden \\ Contact e-mail: mvh@hig.se \\ ${ }^{3}$ Ph.D. Senior Scientist, Sandvik Materials Technology Sweden \\ Contact e-mail: ping.liu@sandvik.com \\ ${ }^{4}$ Dr. Professor, Luleå University of Technology, ${ }^{5}$ AB Sandvik Coromant Sweden \\ Contact e-mail: Inge.Svenningsson@sandvik.com
}

Keywords: Aerospace Material, Titanium (Ti-6Al-4V), Turning, Residual Stress, X-ray Diffraction.

\begin{abstract}
Titanium alloys are used in aerospace industry owing to their high strength to weight ratio. These alloys are considered to be difficult to machine due to their rigidity and poor thermal conductivity. High-pressure jet-assisted machining of titanium alloys is beneficial. It not only increases production efficiency, by increasing the cutting speed and lowering temperature both in cutting zone and the cutting tool, but also improves chip control, and increases tool life. It also produces better surface integrity and compress residual stress, which improves the properties of work metals such as fatigue. In order to compare the effect of high-pressure jet-assisted machining on the work pieces of Ti-6Al-4V alloy, the depth profile of residual stress was measured using $\mathrm{x}$ ray diffraction. As comparison, the depth profile of residual stress was also measured for the conventional machined work pieces. It was found that the residual stress was a function of machining parameters, such as cutting speed, feeding force and depth of cut and particularly the high-pressure jet increases the amount of residual compressional stresses in both cutting and feed direction $[1,2,3]$. In the present paper, Ti6Al4V rod was machined by turning in two different manners, finishing and roughing. Tests were conducted on a lathe using different cooling systems, high pressure and conventional. To illustrate the effect of high-pressure jet assisted machining on the properties of the work piece of Ti-6-Al-4V and the depth profile of its residual stress, X -ray defractometer was used. The maximal amplitude of residual stress, at both the longitude (feeding direction) and transversal (cutting) directions, the depth of compress residual stress and the depth of the total residual stress will be present as the function of the machining parameters.
\end{abstract}

\section{Introduction}

The machinability of titanium is in general comparable to that of stainless steel. With higher alloy content and hardness, the machinability of titanium alloys generally decreases. This is true of most other metals. At a hardness level over $38 \mathrm{Rc}(350 \mathrm{BHN})$ increased difficulty in operations such as drilling, tapping, milling and broaching can be expected. In general, however, if the particular characteristics of titanium are taken into account, the machining of titanium and its alloys should not present undue problems. When cutting titanium, a high shear angle is produced between the workpiece and chip, resulting in athin chip flowing at high velocity over the tool face. High temperatures develop and, since titanium has low thermal conductivity, the chips have a tendency to gall and weld to the tool cutting edges. This speeds up tool wear and failure. 
Short tool life and low productivity due to the low permissible rates of metal removal are often associated with the machining titanium alloys [1]. At the same time the measurement of residual stresses is very important to know the integrity of the surface after turning as a safety factor. A combination of mechanical and thermal affect the residual stresses induced by machining operatins. The pressure of the cutting tool on the work-piece causes plastic deformation, leading to compressive residual stresses at the surface layer. The heat developed by friction between the tool and the work-piece can lead to residual tensile stresse at the surface. The resultant stress on the material depends on the relative importance of each factor [4]. The residual stress distributions due to machining was reported into three different types as shown schematically in Fig.1. The type I curve represents an abusive machining caused by excessive friction heat development, leading to tensile residual stresses. This is the worst stress distribution: tensile stress is generated at the surface and below it. A hard-turned with much worn tool generates this distribution to a specimen. The type III curve shows extremely good machining conditions, when only the surface work hardening is allowed to occure. Crack formation and propagation is prevented by this ideal stress distribution. A new tools without heat generation has such effect. The type II curves corespondes that heat has been introduced, but plastic deformation below the surface has created compressive residual sress at the surface. Type II curve relates to normal machining process, although tool wear could lead to a type I curve [5].

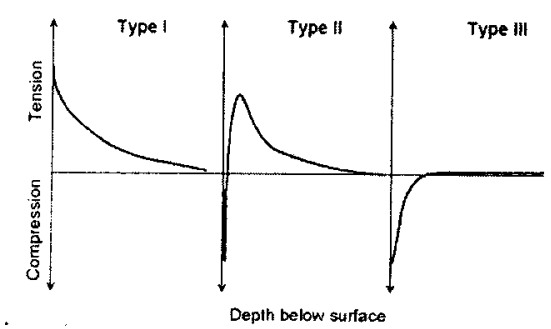

Figure.1: Types of machining stress distribution according to Parrish (1977).

A variation in lattice spacing over that length scale is subjected to the residual stresses on the surface layer vary rapidly over the first micrometer depth from the surface. The cause of this stress distribution is the strong temperature gradient near the surface generated during machining, resulting in a strong modification of phase distributions with surface distance, and in a large shifting of the stress-free lattice spacing. High-pressure jet-assisted machining is starting to establish itself as a method for substantial increase of economical production in the metal cutting industry. Cutting with an excess amount of cutting fluids is still very common, even if a trend towards dry cutting is starting to grow fast. However, many materials such as heat resisted alloys and titanium can not be effectively cut without cooling. Research made in the past has shown the high potential with highpressure jet assisted machining compared to conventional cooling. Methods were focused on turning operation in the pressure range from 2,75 to $280 \mathrm{MPa}$. Water, oil and regular cutting fluids were used. The presented results showed increased tool life, improved surface finish, reduced cutting forces and better chip control [6].

The surface of titanium alloys is considered to easily damage during some traditional machining operations. Damage appears in the form of micro cracks, built up edges, plastic deformation, heataffected zones and tensile residual stresses. In service, this damage can lead to a great degradation of properties such as fatigue strength and stress corrosion resistance. Production engineers and companies specializing in the machining of aerospace materials generally have developed techniques to maximize surface integrity of titanium alloys. Thus, optimum properties usually are achieved during machining of titanium. In applications such as in aerospace industries the maximum fatigue strength is required [6]. Fatigue life of components to be cyclically loaded increases by the introduction of compressive residual stresses in the surface layers. This is due to 
the fact that, for a fatigue crack to propagate, the region at the crack tip must be in a state of tension during some point in the loading cycle. When a residual state of compressive stress has been superimposed over the stress state resulting from service loading, it is possible that most or the entire load spectrum will remain in the compression region. For applications with thousands of rpm, such as gas turbine engine blades, such fatigue enhancements are critical. Cracks initiated by foreign object damage can potentially propagate and result in premature failure.

Residual stress measurement has been carried out at Sandvik Materials Technology for years. In all cases involved in steels, either Fe-base or Ni-base, the Cr-radiation has been preferred. The present investigation was carried out with $\mathrm{Cu}$-radiation as well as $\mathrm{Cr}$-radiation. In this paper the procedure to measure the depth profile of residual stress during metal cutting of titanium alloy (Ti-6Al-4V) assisted by high-pressured jet using x-ray diffraction is established.

\section{Experimental}

\subsection{Material}

The material used in the test was RMI 6AL-4V bar, with the USA specification AMS 4920 and Europpa AECMAprEN3312, an alpha-brta titanium base alloy with anominal composition of 6 percent aluminium and 4 percent vanadium with a hardness of 342 Vickers (HV3). The $0.2 \%$ offset yield strength was $827 \mathrm{MPa}$ and the ultimate tensile strength $917 \mathrm{MPa}$. The chemical composition of the studied material was analyzed at Sandvik Material Technology and the result is given in table.1 (in wt. \%). It showed that the producer's declaration of the material is in phase with lab analysis in table 1 .

Table 1: The chemical analysis of Titanium alloy (wt \%)

\begin{tabular}{cccccccc}
\hline $\mathrm{Fe}$ & $\mathrm{C}$ & $\mathrm{V}$ & $\mathrm{Al}$ & $\mathrm{Ti}$ & $\mathrm{O} \mathrm{ppm}$ & $\mathrm{H} \mathrm{ppm}$ & $\mathrm{N} \mathrm{ppm}$ \\
\hline 0.18 & 0.01 & 4.3 & 6.2 & $\mathrm{Ba}$ & 1560 & 19 & 80 \\
\hline
\end{tabular}

\subsection{Turning condition}

The machining was done on a CNC lathe, Swedturn SMC. The high-pressure was produced by a pump with maximum pressure of $100 \mathrm{MPa}$ with the motor effect $55 \mathrm{~kW}$ at $1500 \mathrm{rpm}$. All tests were performed with cutting fluid water plus $5 \%$ soluble oil so called Coolage $5 \%$ from Castrol. The high-pressure jet was always directed towards the rake face of the insert. The outer diameter of the bar was different for each operation. The turning conditions are summarized in tables 2-3.

Table 2: The tool and insert information.

\begin{tabular}{ll}
\hline \multicolumn{2}{c}{ Tool and insert designation } \\
\hline Tool holder (Coromant) & PRGCL525 P12 \\
\hline $\begin{array}{l}\text { Insert, a round cemented carbide with honed } \\
\text { edge radius } 0.035(\mathrm{~mm})\end{array}$ & RCHT12 04 MO KL \\
\hline Rake angle $(\gamma \mathrm{O})$ & $26^{\circ}$ \\
\hline Insert grade & Uncoated H13AK25 \\
\hline
\end{tabular}

Table 3: The cutting condition.

\begin{tabular}{lll}
\hline \multicolumn{1}{c}{ Cutting data } & Roughing & Finishing \\
\hline Cutting speed vc $(\mathrm{m} / \mathrm{min})$ & 70 & 250 \\
\hline Feed $\mathrm{f}(\mathrm{mm} / \mathrm{rev})$ & 0.4 & 0.2 \\
\hline Depth of cut ap $(\mathrm{mm})$ & 3 & 0.3 \\
\hline Max chip thickness hex $(\mathrm{mm} / \mathrm{rev})$ figure 1 & 0.35 & 0.06 \\
\hline Diameter range D $(\mathrm{mm})$ & $94-128$ & 63 \\
\hline $\begin{array}{l}\text { Pump pressure }(\mathrm{MPa}) \text { with a nozzle of } 0.4 \\
\text { (mm) diameter }\end{array}$ & 28 & 28 \\
\hline
\end{tabular}

\section{3-Sample preparation for residual stress measurement}


From Ti6Al4V machined rods, samples in a plate form were cut. Each plate was cut into three pieces and the outer pieces were used for measurement (figure 2).

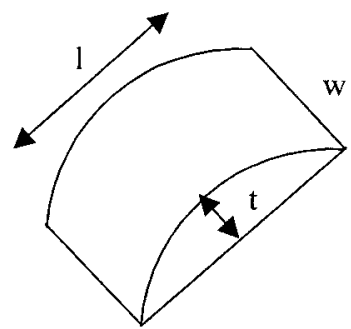

Figure 2: Samples were cut out of a round bar. Typically $10 \mathrm{~mm}$ thick (t) and $30 \mathrm{~mm}$ wide $(\mathrm{w})$ the length (l) is determined by the diameter of the bar.

Samples were electro-chemically polished using electrolyte of $30 \mathrm{ml} \mathrm{HClO}_{4}, 175 \mathrm{ml} \mathrm{n}$-butyl alcohol and $300 \mathrm{ml}$ methanol and at $17 \mathrm{~V}$ and room temperature. The curring density is $0.05-0.10 \mathrm{~A} / \mathrm{cm}^{2}$ and the polishing rate is $\sim 25 \mathrm{~nm} / \mathrm{s}$.

\subsection{Residual stress measurement}

The BRUKER D8 Advance x-ray diffractometer with $1 / 4$ circle Eulerian cradle carried out residual stress measurement. Omega-diffractometer geometry and radiation were utilized [7]. (213) peak of
$\alpha$-Ti was selected.

\section{Results and discussion}

\subsection{Effect of high pressure on turning condition}

Table 4. Roughing cutting data

\begin{tabular}{|c|c|c|c|}
\hline Time $(\mathrm{min})$ & $\mathrm{VB}$ & Sample No. & $\mathrm{Ra}(\mu \mathrm{m})$ \\
\hline 0,5 & 0,18 & 2 & 1.0 \\
\hline 1 & 0,22 & 4 & 0.85 \\
\hline 2 & 0,25 & 3 & 0.72 \\
\hline 5 & 0.36 & 1 & 0.70 \\
\hline
\end{tabular}

Table 5. Roughing cutting data with high-pressure

\begin{tabular}{|c|c|c|c|}
\hline Time $(\mathrm{min})$ & VB & Sample No. & $\operatorname{Ra}(\mu \mathrm{m})$ \\
\hline 0.8 & 0.18 & 8 & 0.84 \\
\hline 2.5 & 0,2 & 9 & 0.95 \\
\hline 5.5 & 0.26 & 10 & 1.26 \\
\hline
\end{tabular}

\subsection{Residual stresses}


Table. 6 Residual stress electro-polished samples at the transversal (T) and longitudinal (L) directions.

\begin{tabular}{|c|c|c|c|c|c|c|c|c|c|c|}
\hline Sample & $T$ & $\mathrm{~L}$ & $T$ & $\mathrm{~L}$ & $\mathrm{~T}$ & $\mathrm{~L}$ & $\mathrm{~T}$ & $\mathrm{~L}$ & $T$ & $\mathrm{~L}$ \\
\hline \multirow{2}{*}{ No.1 } & \multicolumn{2}{|c|}{$0 \mu \mathrm{m}$} & \multicolumn{2}{|c|}{$130 \mu \mathrm{m}$} & \multicolumn{2}{|c|}{$169 \mu \mathrm{m}$} & \multicolumn{2}{|c|}{$200 \mu \mathrm{m}$} & \multicolumn{2}{|c|}{$396 \mu \mathrm{m}$} \\
\hline & $-424 \pm 24$ & $-211 \pm 12$ & $-5 \pm 1$ & $-10 \pm 1$ & $-22 \pm 1$ & $-24 \pm 2$ & $-39 \pm 2$ & $24 \pm 2$ & $-15 \pm 1$ & $-9 \pm 1$ \\
\hline \multirow{2}{*}{ No.2 } & \multicolumn{2}{|c|}{$0 \mu \mathrm{m}$} & \multicolumn{2}{|c|}{$41 \mu \mathrm{m}$} & \multicolumn{2}{|c|}{$104 \mu \mathrm{m}$} & \multicolumn{2}{|c|}{$296 \mu \mathrm{m}$} & \multicolumn{2}{|c|}{$392 \mu \mathrm{m}$} \\
\hline & $-395 \pm 22$ & $-248 \pm 16$ & $-19 \pm 1$ & $-28 \pm 1$ & $-44 \pm 2$ & $-8 \pm 2$ & $-21 \pm 1$ & $-3 \pm 1$ & $-28 \pm 1$ & $2 \pm 1$ \\
\hline \multirow{2}{*}{ No.3 } & \multicolumn{2}{|c|}{$0 \mu \mathrm{m}$} & \multicolumn{2}{|c|}{$17 \mu \mathrm{m}$} & \multicolumn{2}{|c|}{$101 \mu \mathrm{m}$} & & & & \\
\hline & $-430 \pm 23$ & $-284 \pm 16$ & $-15- \pm 1$ & $7 \pm 2$ & $-19 \pm 1$ & $-5 \pm 1$ & & & & \\
\hline \multirow{2}{*}{$\mathrm{No} .4$} & \multicolumn{2}{|c|}{$0 \mu \mathrm{m}$} & \multicolumn{2}{|c|}{$31 \mu \mathrm{m}$} & \multicolumn{2}{|c|}{$45 \mu \mathrm{m}$} & & & & \\
\hline & $-349 \pm 19$ & $-209 \pm 12$ & $-196 \pm 10$ & $-296 \pm 15$ & $-8 \pm 1$ & $-22 \pm 1$ & & & & \\
\hline \multirow{2}{*}{ No. 5} & \multicolumn{2}{|c|}{$0 \mu \mathrm{m}$} & \multicolumn{2}{|c|}{$28 \mu \mathrm{m}$} & \multicolumn{2}{|c|}{$52 \mu \mathrm{m}$} & & & & \\
\hline & $-371 \pm 23$ & $-271 \pm 15$ & $-4 \pm 1$ & $.84 \pm 5$ & $-13 \pm 1$ & $-5 \pm 1$ & & & & \\
\hline \multirow{2}{*}{ No.6 } & \multicolumn{2}{|c|}{$0 \mu \mathrm{m}$} & \multicolumn{2}{|c|}{$28 \mu \mathrm{m}$} & \multicolumn{2}{|c|}{$52 \mu \mathrm{m}$} & \multicolumn{2}{|c|}{$74 \mu \mathrm{m}$} & & \\
\hline & $-381 \pm 25$ & $-324 \pm 17$ & $-144 \pm 7$ & $-276- \pm 20$ & $-19 \pm 2$ & $-75- \pm 6$ & $-7 \pm 1$ & $-9 \pm 1$ & & \\
\hline \multirow{2}{*}{ No.7 } & \multicolumn{2}{|c|}{$0 \mu \mathrm{m}$} & \multicolumn{2}{|c|}{$55 \mu \mathrm{m}$} & \multicolumn{2}{|c|}{$139 \mu \mathrm{m}$} & & & & \\
\hline & $-422 \pm 23$ & $-387 \pm 22$ & $-61+1$ & $-159 \pm 8$ & $-14 \pm 1$ & $4 \pm 1$ & & & & \\
\hline $\mathrm{No} 8$ & & & & & & & & & & \\
\hline No.8 & $-402 \pm 24$ & $-235 \pm 15$ & $-328 \pm 17$ & $-217 \pm 12$ & $-28 \pm 2$ & $.7 \pm 1$ & $-5 \pm 1$ & $-7 \pm 1$ & & \\
\hline No 9 & & & 52 & $\mathrm{~m}$ & & & & & & \\
\hline No.9 & $-356 \pm 23$ & $-219 \pm 13$ & $-18 \pm 2$ & $-28 \pm 2$ & $0 \pm 0$ & $-10 \pm 2$ & & & & \\
\hline Nolo & & & & & & & & & & \\
\hline Nolo & $-334 \pm 20$ & $-194 \pm 13$ & $.87 \pm 5$ & $-97 \pm 5$ & $-22 \pm 2$ & $-27 \pm 2$ & $-2 \pm 1$ & $-13 \pm 1$ & & \\
\hline
\end{tabular}

In order to show the effects of high-pressure the depth profiles of residual stress were plotted between the roughing cutting and roughing cutting data with high-pressure for a similar cutting time and the comparisons are shown in Figs. 3-5 for the pair of samples No.4-No.8, No.3-No.9 and No.1-No. 10 respectively.

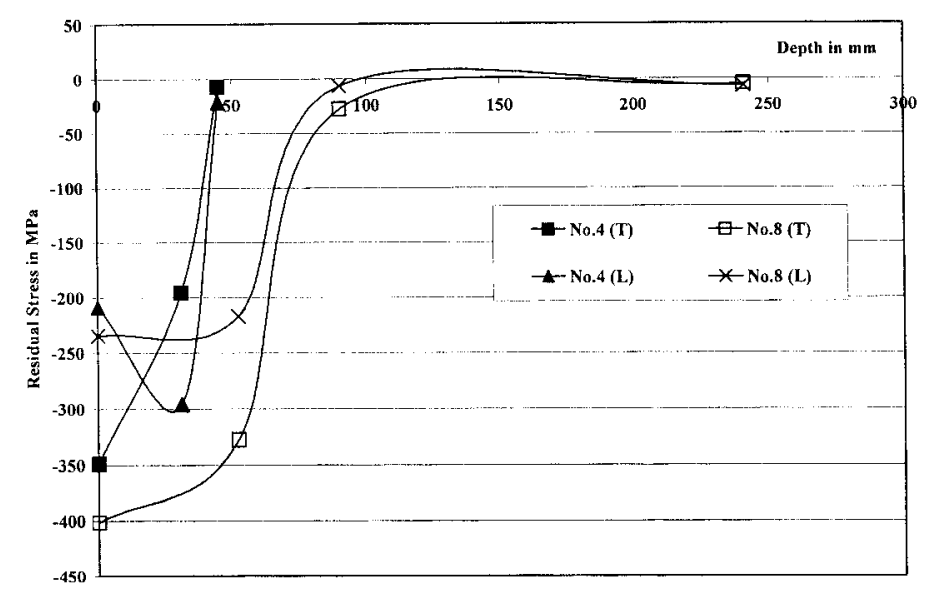

Fig.3. The comparison of depth profiles of Sample No.4 with No.8. 


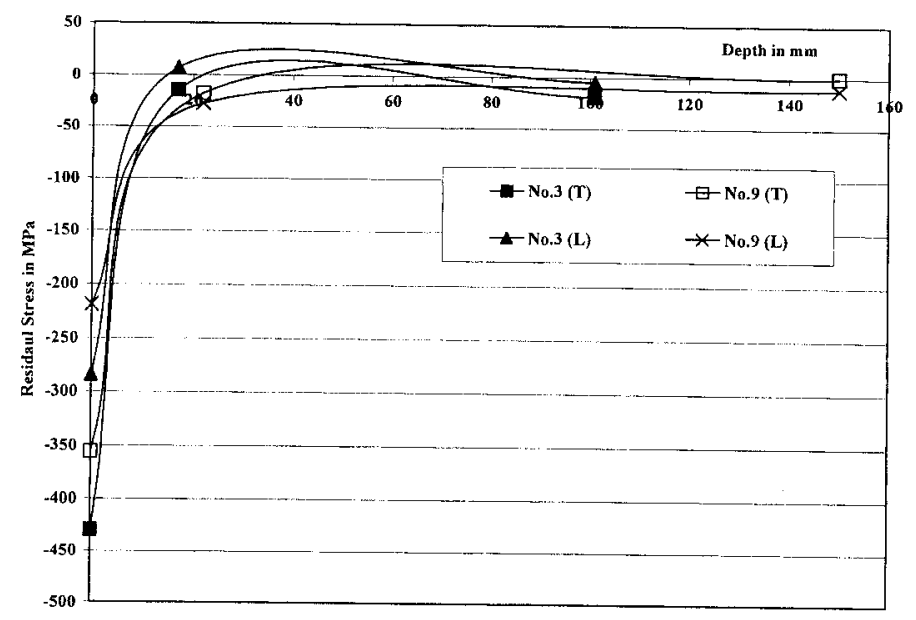

Fig.4. The comparison of depth profiles of Sample No.3 with No.9.

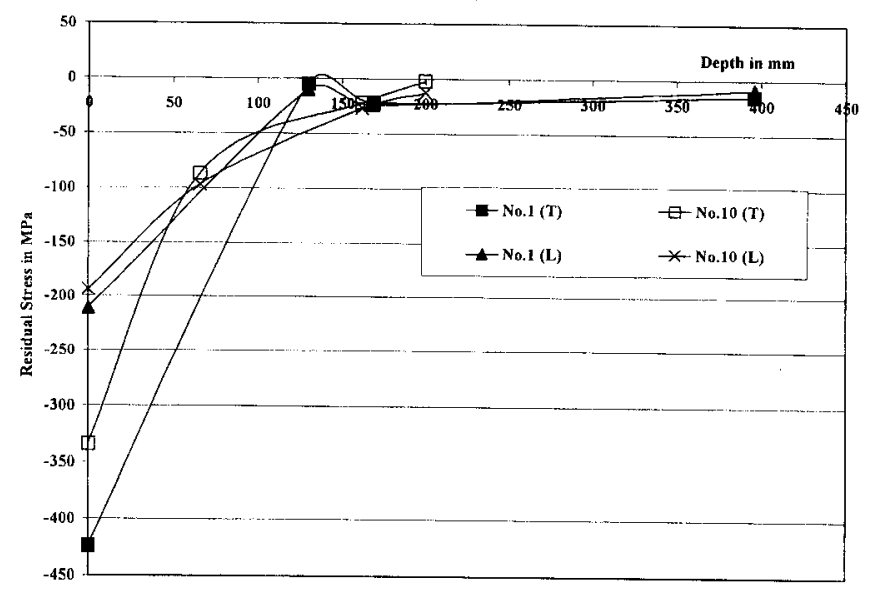

Fig.5. The comparison of depth profiles of Sample No.1 with No.10.

It noteworthy that roughing cut resulted in compress residual stress in all case: between -200 to $250 \mathrm{MPa}$ at the longitudinal direction (L) and between -350 to $-400 \mathrm{MPa}$ at the transversal direction $(\mathrm{T})$. Thus, the residual stresses are much higher at the transversal direction (T) than at longitudinal direction $(\mathrm{L})$. The difference is larger than $100 \mathrm{MPa}$.

High-pressure jet did not always result in higher amplitude of residual stress as in the cases shown in Figs. 4 and 5. However, as can be seen high-pressure jet induced a much deeper compress residual stress under similar cutting condition in all cases. The effected layer by cutting increased from $\sim 45 \mu \mathrm{m}$ for sample No. 4 to $\sim 90 \mu \mathrm{m}$ for sample No.8 (Fig.3); from $\sim 17 \mu \mathrm{m}$ for sample No. 3 to $\sim 52 \mu \mathrm{m}$ for sample No.9 (Fig.4) and from $\sim 130 \mu \mathrm{m}$ for sample No.1 to $\sim 200 \mu \mathrm{m}$ for sample No.10 (Fig.5).

Thus, the layers effected by cutting are nearly double although the amplitude of the compress residual stress was not greatly effected by high-pressure jet during cutting. 


\section{Conclusion}

Roughing cutting resulted in fairly high compress residual stress on the titanium alloy. The residual stresses are higher at the transversal direction (T) than at longitudinal direction (L) for all samples.

High-pressure jet did not greatly effect the amplitude of the compress residual stress but highpressure jet induced compress residual stress nearly twice as deep as the convetion roughing cutting.

\section{Acknowledgments}

The author would like to thank Sandvik Coromant in Sandviken Sweden for supplying machining and other surface treatment and Sandvik Materials Technology for doing the residual stress measurements.

\section{References}

[1] R. E. Goosey, Metals and Materials, 1989, vol.5, pp. 451-454

[2] E. M. Trent, Metal Cutting, Third edition, 1991, Butterworth-Heinemann Ltd., Oxford, pp. 237-241.

[3] H. E. Chandler, Metals Handbook, $9^{\text {th }}$ edition, Vol.6, Machining, ASM International, Metals Park, OH 44073, 1989, pp. 844.

[4] Parrish,G. (1977). Heat Treat.Met.4, 107-116.

[5] Vomacka, P.\& Walburger,H.(2000). Mater. Sci. Forum, 347-349, 592-597. (Proceeding of the $5^{\text {th }}$ European Conference on Residual Stresses).

[6] Manuchehr Vosough, 2002-02-20, A Literature Study of High Pressure Cooling "Jet Break" And Turning in Titanium, Department of Applied Physics and Mechanical Engineering Division of Manufacturing Systems Engineering The Cirius Laboratory, pp. 17.

[7] A. Turnbull, ER de los Rios, R.B. Tait, C. Laurant, and J.S. Boabid: Fatigue Fract. Eng.Mater. Structures, 1998, vol. 21, pp. 1513-24. 
Residual Stresses VII, ICRS7

doi:10.4028/www.scientific.net/MSF.490-491

Depth Profile of Titanium Alloy (Ti-6Al-4V) and Residual Stress Measured by Using XRay Diffraction after Metal Cutting Assisted by High-Pressured Jet Cooling Evaluation of Etching Methods: ION Beam (EDOS) and Electro-Chemical Etching doi:10.4028/www.scientific.net/MSF.490-491.545 